\title{
Re-thinking Teacher Professional Development through Schön's Reflective Practice and Situated Learning Lenses
}

\author{
Victor Pitsoe \\ Mago Maila \\ Department of Leadership \& Management, \\ College of Education, University of South Africa \\ Email address: Pitsovj@unisa.ac.za
}

\section{Doi:10.5901/mjss.2013.v4n3p211}

\begin{abstract}
Schön's notion of reflective practice was a reaction against an instrumental notion of teaching where the teacher is a technician implementing others' knowledge in practice - it is a rejection of technical rationality for reflectivity. Hence, there is a need for changing from a technical-rationality model towards a model that encourages internalisation. Drawing from Schön's framework of reflective practice, situated learning theory, and Freire's critical pedagogy, we argue that TPD should be approached from a reflective practice and situated learning perspective.
\end{abstract}

Keywords: Reflective practice, Teacher Professional Development, situated learning, technical rationality, critical pedagogy.

\section{Introduction}

Reflective practice and situated learning are widely accepted and used as developmental practices for organisations, networks and individuals. For example, both are accepted as being key components of professional education and practice in health and social care. Thus, Teacher Professional Development's (TPD) apparent obsession with reflection and reflective practice is due to the influence of Donald Schön's and John Dewey's work and the experientialist education movement which seeks to address a technical rationality or an applied science view of human skill. TPD relies on powerful practices in learning: reflection, critical dialogue and collaboration. It is critical to the efforts to improve South African schools. Increasingly, the emerging trends in the TPD discourses are dominated by John Dewey's and Schön. On the one hand, Dewey believed that teachers should take time to reflect on their observations, knowledge, and experience so that they can effectively nurture each child's learning. On the other hand, Schön's notion of reflective practice was a reaction against an instrumental notion of teaching where the teacher is a technician implementing others' knowledge in practice - it is a rejection of technical rationality for reflectivity. Technical reflection, which is related to technical rationality and which focuses on specific technical issues in performance, consists of responses that deal with the technical application of educational knowledge and basic curriculum principles, such as are the students doing what the teacher asked them to do (Schön, 1983a:21).

In teacher education context, reflective practice implies that the teacher examines his/her own teaching methods in the light of how well students are learning, determining in collaboration with colleagues or coaches how to improve one's practice, examining the results of an intervention and making any necessary changes. Much has been discussed and written in recent years about reflection and situated learning theory and their applications to Higher Education teaching and learning environments. Little, if any, has been said about the implications of these ideas and reflective pedagogy in teaching practices for TPD in South African context, more specifically in equipping teachers with skills (classroom management, curriculum issues relating Curriculum Assessment Policy Statements (CAPS). Reflective practice is becoming a leading paradigm in teacher education programs worldwide. It has, however, the potential to help practitioners in all fields unlock the tacit knowledge and understanding that they have of their practice and to use this to generate knowledge for future practice. Since reflective practice enables teachers to think about what, how and why they do reflect, it allows them to step out of routine action and make adaptations to match the needs of the learners. The primary benefit of reflective practice for teachers is a deeper understanding of their own teaching style and, ultimately, greater effectiveness as a teacher. Other specific benefits noted in current literature include the validation of a teacher's 
ideals, beneficial challenges to tradition, the recognition of teaching as artistry, and respect for diversity in applying theory to classroom practice.

Professional learning is not a fixed construct - it is strongly shaped by the context in which the teacher practices. This is usually the classroom, which, in turn, is strongly influenced by the wider school culture and the community and society in which the school is situated. Teachers' daily experiences in their practice context shape their understandings, and their understandings shape their experiences (Timperley, 2008:6). Thus, the fluid nature of the teachers training needs demands a revitalised framework of effective professional development consistent with reflective practice and Kolb's theory, focusing not on the mastery of static content but rather on the construction of meaning within a collaborative environment.

This article recognises that, like any other area of work, we face certain challenges when using reflective practice. In this article we argue that TPD should be approached from a reflective practice and situated learning perspective. There is need to the need for change from technical-rationality model towards a model that encourages internalisation. Drawing from Schön's framework of reflective practice, situated learning theory, and Freire's critical pedagogy, this article (1) conceptualises reflective practice; (2) explores Schön's framework of reflective practice in TPD and teacher education; (3) explores understanding TPD through the situated learning lens; (4) explores insights on reflective practice and TPD; (5) investigates the implications of reflective practice and situated learning for TPD; and lastly, (6) proposes a shift towards situated learning and reflective practice in TPD.

\section{Conceptualising reflective practice}

To start with, "What is reflection?" and "How do we conceptualise reflective practice for the purpose of helping qualified and student teachers to become reflective practitioners?". Although John Dewey who is often considered to be the originator of the concept of reflection, reflective practice is a very old concept - it has an extensive history as far back as the Greek philosophers. For example, it can be traced back to the Socratic method of enquiry - in which questioning and exploration of the implications of another's viewpoint are employed to enlighten the enquirer. Reflection as a slogan for educational reform also signifies a recognition that no matter what we do in our teacher education programs and how well we do them, at best we can only prepare teachers to begin teaching (Zeichner, 2008). In addition, when embracing the concept of reflective teaching, there is often a commitment by teacher educators to help prospective teachers internalise during their initial training the dispositions and skills to learn from their teaching experience and become better at it throughout their teaching careers.

Reflection is perceived as a critical attribute of competent teachers who are prepared to address these challenges (Boud et al., 1985; Moon 2004; Schön, 1983, 1987; Larrivee and Cooper 2008; Osterman and Kottkamp 2004). It is an important human activity in which people recapture their experience, think about it, mull over and evaluate it (Boud, Keogh and Walker, 1985: 43). It is this working with experience that is important in learning. Proponents of reflective practice hold that reflective teachers have the capacity to reflect on their teaching practices and their actions by taking wider historical, social and political contexts into consideration; to make informed decisions; to change their practices accordingly; thus, they can take the responsibility of their teaching. On the other hand, Braun and Crumpler (2004:60) maintain that "to be unreflective... results in a teacher who is merely a skilled technician, i.e. one who has limited ability to make good decisions; to consider the consequences of their actions; and, to alter their actions".

Reflective practice is a term that carries diverse meaning. Central to reflective practice is the assumption that the quality of our actions is not independent of the thinking we are able to do before and in the process of the action. For Reid (1993:305), reflection is a process of reviewing an experience of practice in order to describe, analyse, evaluate and so inform learning about practice. Reflective practice is more than thoughtful practice. It is that form of practice that seeks to problematise many situations of professional performance so that they can become potential learning situations and so the practitioners can continue to learn, grow and develop in and through practice (Jarvis, 1992:180). Moon (1999) defines reflective practice as "a set of abilities and skills, to indicate the taking of a critical stance, an orientation to problem solving or state of mind". In essence, it is a readiness to constantly evaluate and review your practice in the light of new learning (which may arise from within the context of your professional practice).

Reflective practice can also be defined in terms of action research, whereby specific problems (in specific settings) are targeted and a continuous feedback mechanism established in order to inform ongoing development of practice (Hopkins and Antes, 1990). Reflective practice has also been defined in terms of action research. Action research, in turn, is defined as a tool of curriculum development consisting of continuous feedback that targets specific problems in a particular school setting (Hopkins \& Antes 1990). As such, it has become a standard concept in teacher education 
programs. Reflective practice is self-regulated, and engages the learner in a process of relating theory and practice (Pavlovich, 2007).

Although the term reflective practice is interpreted and understood in different ways, within this discourse it is about: the awareness of the knowledge we use, how that use is and how we can improve our action in real time; how our minds work and how we use and create theories in practical situations; invisible and visible, tacit and explicit, blindness and sight; and flexibility, adaptation and effectiveness. Also, reflective practice focuses on the relationship between action and thinking; the kind of thinking that shapes our actions - before, during and after the action; and deals with the interaction between practice, reflection, thinking, learning and performance. Reflective practice is driven by questions, dialogue, narratives and stories; fundamentally structured around inquiry; and is a mode that integrates or links thought and action with reflection. It involves thinking about and critically analysing one's actions with the goal of improving one's professional practice (Imel, 1992:8).

\section{Schön's framework of reflective practice in TPD and teacher education}

Schön has made a remarkable contribution to our understanding of the theory and practice of learning. His work on learning systems fed well into a very significant collaboration with Chris Argyris around professional effectiveness and organisational learning. He provides a framework that not only addresses these cognitive and organisational barriers, but distinctly illuminates the practice of reflectivity as well. Experiential learning theorists, among others, including Dewey, Lewin and Piaget, maintain that learning begins with experience, and specifically problematic experience. Reflective practice then, integrating theory and practice, thought and action, is, as Schön (1987:31) described, a "dialogue of thinking and doing through which I become more skilful". Schön (1987) developed Dewey's notion of reflection with the concept of "reflectionin-action". Reflection-in-action is a reflective conversation with the materials of a situation, each person carries out his own evolving role... "listens" to the surprises ("back talk") that result from earlier moves, and responds through on-line production of new moves that give new meanings and directions to the development of the artifact (Schön, 1987:31).

Schön's work has an historical foundation in a tradition of learning supported by Dewey, Lewin, and Piaget, each of whom advocated that learning is dependent upon the integration of experience with reflection and of theory with practice (Imel, 1992:2). Schön maintained that the stage is set for reflection when "knowing-in-action" - the sort of knowledge that professionals come to depend on to perform their work spontaneously - produces an unexpected outcome or surprise. This surprise ("back talk") can lead to one of two kinds of reflection: reflection on action, which occurs either following or by interrupting the activity, or reflection in action, which occurs during (without interrupting) the activity by thinking about how to reshape the activity while it is underway (Imel, 1992:2). Ashcroft and Foreman-Peck (1994:3) note that the critical part of reflective practice is that it requires a commitment to learning from experience and from evidence, rather than to learning certain 'recipes' for action. Even if you start with recipes, they need to be explored and analysed for their underlying assumptions and effects as you gain in confidence. This process of critical enquiry should be reflexive, that is, responsive to your own needs and the context in which you work, but also critical of the existing educational provision and ideology (including your own). The analysis involves not just your own practice, but also the social, moral and political context for that practice (Ashcroft and Foreman-Peck, 1994:3).

Against this backdrop, Shon's reflective practice framework has a critical role to play in the designing of training programmes in TPD and teacher education. The model of reflective practice could be to teacher learning as well as to teaching arguing that the TPD practitioner's role is to facilitate the development of teachers as reflective practitioners of their subject. Reflective framework of teaching and learning is not only the most valid distinguishing feature but also the key to an understanding of how the two can be usefully related in practice. Reflective practice can be used to identify problems; action research can seek to provide solutions.

\section{Understanding TPD through the situated learning lens}

Reflective practice is associated with situated learning and communities of practice. On one hand, situated learning usually goes beyond a real world context, and also includes other social participants in the learner experience. On the other hand, communities of practice are formed by people who engage in a process of collective learning in a shared domain of human endeavour. In a situated learning setting, the social interaction that occurs in communities of practice between experts and novices is crucial to the theory of situated cognition or learning. From an epistemological perspective, situated learning theory aligns with constructivism, which posits that learners construct meaning from their 
experiences. Constructivism occurs on a continuum from cognitive to social to radical, varying on the subjective or objective nature of knowledge or reality (Roberts, 2006:18). On one end of the continuum, cognitive constructivism assumes that knowledge is objective and separate from the learner. The learner's construction of knowledge is a reconstruction of what truly exists. On the other end of the continuum, radical constructivism assumes that all knowledge is subjective and constructed within the individual learner. Social constructivism lies in the middle and assumes that knowledge is subjective, but constructed through a shared social system. The individual learner constructs meaning, based on the socially defined nature of that knowledge.

Learning is an integral part of generative social practice in the lived-in world, and a situated activity (Lave and Wenger, 1991:33-35). In more general terms, when an actor reflects on a situation and the actions taken in it, and perhaps also on other similar situations, he or she may develop a conscious network of concepts, characteristics, principles, and so on, helpful in describing practice (Korthagen, 2009:5). Such a mental network is called a schema. The schemas are developed through socialisation into argumentative discourse in dialogic collective settings. Schema play a very important role in the learning process, and are comprise of the structural and functional commonalities students have acquired from their experience with argumentation. For example, an individual disposition to support his or her claims with reasons will come from participating in discussions where students are prompted to provide reasons for their positions or where they are able to appreciate the benefits of asking peers to justify their views (Reznitskaya, 2003:1). Thus, practices present in a dialogic discussion, such as generating and challenging each others' reasons, or questioning assumptions, are "psychological tools". Learning contexts are socially dynamic and dialectically performed: "social practices are produced and reproduced in activity in the world, dialectally, rather than exclusively within or between persons" (Lave 1988:193).

As communities of practice, teachers often are (maybe unconscious) designers of their own environments and situations which are relevant for learning, but this is frequently a tacit knowledge where the theories they use are not made explicit (Krumsvik, 2008:13). Situative theorists focus on the social nature of learning and the central role that communities of practice play in determining what and how people learn. From a situative perspective, learning is both an individual process of coming to understand how to participate in the discourse and practices of a particular community, and a community process of refining norms and practices through the ideas and ways of thinking that individual members bring to the discourse (Krumsvik, 2008:13). In educational settings, a situative perspective suggests that strong professional learning communities can foster the enhancement of teachers' professional knowledge and improvement of practice.

The situated theory asserts that knowledge does not exist in its own world or merely in the mind of the individual, but that it is divided and is a part of participation in a cultural practice (Krumsvik, 2008:17). Situated learning theory shifts attention from individual minds to connections among minds; and from the properties of individual persons or of their environments to the interactions between people, and between people and their environment (Yuan and McKelvey, 2004:68). Learners are not isolated individuals but participants within communities of practice. In addition, it follows that (a) individual learning is inseparable from collective learning; and (b) situated learning should be understood primarily as evolving within "an interactive context and is embedded in the context and the process of organising" and is "best modelled in terms of the organizational connections that constitute a learning network" (Yuan and McKelvey, 2004:68). Situated learning theory proponents (Greeno, Collins and Resnick, 1996; Yuan and McKelvey, 2004; Krumsvik, 2009) maintain that the contexts and activities in which individuals learn are fundamental to what they learn. They argue that learning activity takes place not only within the individual learner's mind, but also among learners within an interactive community. Situated learning theory advocates a fundamental reconceptualisation of the processes of human cognitive activities. Thus, a focus on the situated nature of knowing and learning suggests that teachers' own classrooms are powerful contexts for their learning.

In light of the above, teacher education and TPD qualifies to be approached from a situated learning perspective it is connected to the situative/pragmatist-sociohistorical view. This view is consistent with changes in organisational studies in the emerging paradigm. The first one is the shift from viewing organisations as linear information processors to treating them as complex adaptive systems (Yuan and McKelvey, 2004:69). Secondly, it reflects the studying learning from a holistic, emergent, multi-level mutual-causality perspective in the context of TPD.

\section{Insights on reflective practice and TPD}

In the discipline of teacher education, reflection has become an "academic virtue and source of privileged knowledge" (Lynch, 2000: 26). Fendler (2003:16) asserts that reflective teaching has been an issue for so long that the debates have 
grown to include several generations of commentaries including examples of teachers' reflective practices. Hence, reflective practice is a beneficial process in teacher professional development, both for pre-service and in-service teachers. As noted by Schön (1983b), the capacity to reflect on action so as to engage in a process of continuous learning was one of the defining characteristics of professional practice. He argued that the model of professional training which he termed "Technical Rationality" - of charging students up with knowledge in training schools so that they could discharge when they entered the world of practice, perhaps more aptly termed a "battery" model - has never been a particularly good description of how professionals "think in action", and is quite inappropriate to practice in a fastchanging world. Technical-rationality is a positivist epistemology of practice. It is "the dominant paradigm which has failed to resolve the dilemma of rigour versus relevance confronting professionals". Schön looks to an alternative epistemology of practice in which the knowledge inherent in practice is be understood as artful doing.

Reflective practice is widely recognised as a central tenet of the teaching and learning process (Harford and MacRuairc, 2008). It is seen by many teacher-education practitioners to be at the very heart of effective teacher preparation programs and the development of professional competence. Farrell (2008) notes that using reflective practice in teacher professional development is based on the belief that teachers can improve their own teaching by consciously and systematically reflecting on their teaching experiences. As reflective practitioners, teachers can use the data gathered from these systematic reflections. Its resonance with teaching is attributable to the fact that it encapsulates the complex, analytical and inquiring nature of teaching at a time when the profession is under attack by a range of discourses emanating from the new managerialist perspective and the competency-driven agenda associated with performativity (Harford and MacRuairc, 2008).

Storytelling and narratives play a critical role in reflective practice involves. They both rely heavily on intuition and have a spiritual nature. For student teachers, reflections can be oral, shared with peers or teachers. Schön (1988) discussed storytelling as a mode of reflection:

"...for storytelling is the mode of description best suited to transformation in new situations of action.... Stories are products of reflection, but we do not usually hold onto them long enough to make them objects of reflection in their own right.... When we get into the habit of recording our stories, we can look at them again, attending to the meanings we have built into them and attending, as well, to our strategies of narrative description."

Accordingly, in the form of storytelling, teachers who engage in reflective practice can develop a deeper understanding of their teaching, assess their professional growth, develop informed decision-making skills, and become proactive and confident in their teaching (Farrell, 2008). Through storytelling and dialogue, the teacher-education practitioner is no longer merely the-one-who-teaches, but one who is himself taught in dialogue with the teachers, who in turn while being taught also teach. They become jointly responsible for a process in which all grow. In this process, arguments based on "authority" are no longer valid; in order to function, authority must be on the side of freedom, not against it. Here, no one teaches another, nor is anyone self-taught. People teach each other, mediated by the world, by the cognisable objects which in banking education are "owned" by the teacher-education practitioner. Critical pedagogy is based on the assumption that there is only one approach to non-oppressive knowledge and cultural practices: namely, critical reflection or what Freire called conscientisation. For this reason, critical reflection can be seen as the basis of a "liberatory praxis" and to becoming a fully developed human being.

Schön's reflective practice has been significant - with many training and education programmes for teachers and informal educators adopting his core notions both in organising experiences and in the teaching content. It involves thoughtfully considering ones experiences as one makes the connection between knowledge and practice, under the guidance of an experienced professional within ones discipline. Thus, professional development through reflective practice can be seen as an opportunity to enter a process of "mental growth spurred from within" where teachers are supported in seeking their own growth. Reflective practice takes place along a continuum, where "people vary in opportunity, ability, or propensity to reflect". Through reflective practice teachers are able to rethink the methods and practices they use in their teaching. Reflective practice has a considerable number of benefits for TPD. Among others, McKay (2007) mentions that it frees teachers from routine behaviour, enables teachers to act in a deliberate manner and improves teaching practice.

\section{Implications of reflective practice and situated learning for TPD}

There is a longstanding recognition in the field of teacher education that reflective practice can be a valuable process in TPD, both for pre-service and in-service teachers. More recently, Farrell (2007) noted that the use of reflective practice in 
TPD is based on the belief that teachers can improve their own teaching by consciously and systematically reflecting on their teaching experiences. According to Gimenez (1999:135), teacher thinking has been defined as research that has a "concern with the ways in which knowledge is actively acquired and used by teachers and the circumstances that affect its acquisition and employment". However, the idea of incorporating reflective practice in TPD stems from a significant number of factors. Among others, it includes the popularity of cognitive as opposed to behavioural psychologies, the birth of research on teacher thinking, views of educational research that have given greater access to teachers' voices and perspectives on their work, and the birth of research on teacher thinking.

Schön's notions of reflection-in-action and reflection-on-action are influential in definitions that distinguish the moments of reflection. It enables the teachers apply to interaction with students (reflection-in-action) and planning and post-lesson thoughts (reflection-on-action). Research on professional development is scattered throughout subject areas, with its focus ranging from classroom processes and structures to teachers' personal traits. Effective professional development should improve teachers' knowledge of the subject matter that they are teaching, and it should enhance their understanding of student thinking in that subject matter. However, research (Phillips 2008) suggests that improving teacher quality can improve learning outcomes for students. Good teachers form the foundation of good schools, and improving teachers 'skills and knowledge is one of the most important investments of time and money that local and national leaders make in education

Reflective practice has implications for TPD. For example, research (Gimenez,1999:133) suggests that TPD programs that embrace reflective practice usually have one of the following aims which reveal how reflection is in fact understood: to enable teachers to analyse, discuss, evaluate and change their own practice, adopting an analytical approach towards teaching; to foster teachers' appreciation of the social and political contexts in which they work, to help teachers recognise that teaching is socially and politically situated and that the teacher's task involves an appreciation and analysis of that context; to enable teachers to appraise the moral and ethical issues implicit in classroom practices, including the critical examination of their own beliefs about good teaching; to encourage teachers to take greater responsibility for their own professional growth and to acquire some degree of professional autonomy; to facilitate teachers' development of their own theories of educational practice, understanding and developing a principled basis for their own classroom work; to empower teachers so that they may better influence future directions in education and take a more active role in educational decision-making.

To sum up, reflective practice is in fact a more systematic approach to aspects of teaching. Reflection can help our understanding of how learning takes place; it can also help teachers guide their own development. Thus, it calls for an approach that gives teachers more power to direct and control their process of reflection.

\section{Towards reflective practice in TPD}

It could be argued that the era of teaching as reflective practice began with the discourse as to whether teaching is an art or a science. Practitioners of science-based professions are usually seen as technical problem solvers. This model of technical rationality suggests that applied research dictates all necessary procedures, but this is not always true within teaching. For this reason, Schön (1983a) argued that a rational, technical, problem solving description of what professionals do is incomplete, and stressed the importance of the artistry of professional action. He saw as an essential component of professional action redressing the balance between the science basis and artistry basis within teaching. At a philosophical level, technical rationality is underpinned by behaviourist and banking education principles.

Flowing from the above, current TPD in the South Africa education system departs on a "one-size-fits-all" approach and cascade model, and is based on the behaviourist principles which focus on input and transmission of knowledge. It is also informed and guided by theory and practice of banking education principles. In the banking method of education passive teacher (as learners in the process) receive deposits of pre-selected, ready-made knowledge. This approach is also referred to as "digestive" and as "narrational" education. At any level, teacher-education practitioner and teacher relationships divulge narrative character. From a philosophical perspective, current TPD approach find itself trapped into banking education and Traditional Cognitive Learning Theory. Thus, it becomes an act of depositing, in which the teachers are the depositories and the teacher-education practitioner is the depositor. At the heart of the banking education is the assumption that the learner's mind is an empty vault into which the riches of approved knowledge are placed. Paulo Freire maintained that in the banking concept of education, knowledge is a gift bestowed by those who consider themselves knowledgeable upon those whom they consider to know nothing. Implicit in the banking concept is the assumption of a dichotomy between human beings and the world: a person is merely in the world, not with the world or with others; the individual is spectator, not re-creator (Freire, 1999). In this view, the person is not a conscious being 
(corpo consciente); he or she is rather the possessor of a consciousness: an empty "mind" passively open to the reception of deposits of reality from the world outside. From the banking notion, teacher-education practitioner's role is to regulate the way the world "enters into" the teachers.

The cascade model lacks reflective practice attributes. Reflective practice offers practical options to enhance professional development issues and it encourages practitioners to generate and share their insights and theories about teaching. For this reason, reflective practice needs to be internalised as part of a teacher's professional identity; it cannot simply be bolted on as an additional skill, rather it becomes part of the professional mind-set and it is integrated within all the competences in a holistic way. In most cases, one-size-fits-all training and cascade model result in an unreflective practice. Teachers who are unreflective about their teaching tend to accept the everyday reality in their schools and "concentrate their efforts on finding the most effective and efficient means to solve problems that have largely been defined for them by (some) collective code" (Zeichner and Liston, 1996:9). It is not that unreflective teachers aren't thinking - but rather that their thinking does not allow the possibility of "framing problems" in more than one way. Schön (1988) suggests that professionals learn to reflect in action by first learning to recognise and apply standard practice rules and techniques, then to reason from general rules to problematic cases characteristic of the profession, and only then to develop and test new forms of understanding and action when familiar patterns of doing things fail. Reflective practice is the pivotal element of experience-based learning. Leitch and Day (2000:179) indicate that the evaluation of the impact of such approaches to teacher reflection has indicated that they not only provides the individual with opportunities for profound re-evaluation, but have also led frequently to powerful changes within the teachers' practices.

The rebirth of interest in critical pedagogy and reflective practice, among others, may be due in part to other emergent trends in education, such as a renewed interest in situated learning theory. Situated learning theory regards reflection as a central factor in the teaching and learning process. Thus, a shift from behaviourist to situated learning calls TPD theoretical framework that is compatible to the emergent paradigm and Freirean pedagogy. From Freirean framework, TPD education should be seen as the practice of freedom - as opposed to education as the practice of domination. Freire taught that "education in the service of liberation" could dislodge students from intellectual stasis and rigid conformity to the status-quo. According to Freire (1999), education has the potential to empower students to respond thoughtfully to the social controls that sustain and undergird oppression. Flowing from this, there is a need to shift towards liberating education framework in TPD. Liberating education consists in acts of cognition, not transferrals of information (Freire, 1999).

\section{Conclusion}

Reflective practice is used at both the pre-service and in-service levels of teaching. Schön's work on reflective practice has been significant - with many training and education programmes for teachers and informal educators adopting his core notions both in organising experiences and in the teaching content. Hence, there are also many calls for reform towards a reflective pedagogy in TPD. Teaching should no longer be seen (if it ever honestly could) as understandable solely in technical-rational terms, which lead to instrumental answers to practical questions. The relationship between theory and practice in teaching cannot be understood solely in terms of rules, principles, techniques and "know-how" derived from empirical-analytical research. Thus, to ensure effective and efficient TPD in South African education system, this article proposes that future training programmes should be guided and informed by the principles consistent with reflective practice, situated learning theory and critical pedagogy - which have the potential to transform traditional teaching practices and develop reflective teachers (practitioners).

\section{References}

Ashcroft, K. \& Foreman-Peck, L. (1994). Managing Teaching and Learning in Further and Higher Education. London: Falmer.

Boud, D, Keogh, R. \& Walker, D. (1985). Reflection Turning Experience into Learning. Kogan Page, London.

Braun, J.A. \& Crumpler, T.P. (2004). The social memoir: An analysis of developing reflective ability in a pre-service methods course. Teaching and Teacher Education, 20 (1): 59-75.

Farrell, T.S.C. (2007). Reflective language teaching: From research topractice. London: Continuum Press.

Farrell, T.S.C. (2008). Reflective Practice in the Professional Development of Teachers of Adult English Language Learners. Center for Applied Linguistics: Brock University, Ontario.

Fendler, L. (2003). Teacher Reflection in a Hall of Mirrors: Historical Influences and Political Reverberations. Educational Researcher, 32(3): $16-25$.

Gimenez, T. (1999). Reflective teaching and teacher education contributions from teacher training. Linguagem \& Ensino, 2(2): 129-143. 
Greeno, JG, Collins, AM \& Resnick, LB (1996). Cognition and learning, in Handbook of educational psychology, edited by D Berliner \& R Calfee. New York: Macmillan: 673-708.

Hanks, W.F. (1991). Foreword by William F. Hanks. In: J. Lave \& E. Wenger. (Eds.). Situated learning. Cambridge University Press: Cambridge.

Harford, J. \& MacRuairc, G. (2008). Engaging student teachers in meaningful reflective practice. Teaching and Teacher Education, 24.

Hopkins, CD \& Antes, RL. (1990). Educational Research: A structure for inquiry. 3rd Ed. Itasca, Illinois: FE Peacock.

Imel, S. (1992). Reflective Practice in Adult Education. ERIC Digest 122: ED346319.

Jarvis, P. (1992). Reflective practice and nursing. Nurse Education Today 12:174-181.

Kolb, D.A. (1984). Experiential learning: Experience as the source of learning and development. Prentice Hall, New Jersey.

Korthagen, F.A.J. (2009). Situated learning theory and the pedagogy of teacher education: Towards an integrative Teaching and Teacher Education 2009), doi:10.1016/j.tate.2009.05.001

Krumsvik, R. (2008). The view of knowledge and the new national curriculum in Norway. US-China Education Review, 5(7) (Serial No.44): 13-28.

Larrivee, B \& Cooper, JM. (2006). An educator's guide to teacher reflection. Boston: Houghton Mifflin Company.

Lave J. \& Wenger E. (1991). Situated learning: Legitimate peripheral participation. Cambridge University Press: Cambridge.

Lave, J. (1988). Cognition in practice: Mind, mathematics, and culture in everyday life. Cambridge, UK: Cambridge University Press.

Leitch, R. \& Day, C. (2000). Action Research and Reflective Practice: towards a holistic view. Educational Action Research, 8(1).

Lipsky, M. (1971). Street-level bureaucracy. An introduction in Hill, M. (Ed.) (1993) The Policy Process Harlow: Pearson Education Ltd.

Lynch, M. 2000. Against reflexivity as an academic virtue and source of privileged knowledge. Theory, Culture and Society, 17(3): 26-54.

OECD (Organisation for International Co-operation and Development). (2009). Teaching and Learning International Survey (TALIS). Paris: OECD.

Phillips, P. (2008). Professional development as a critical component of continuing teacher quality. Australian Journal of Teacher Education, 33(1): 1-9.

McKay, S.L. (2007). Reflective Teaching Practices. Teacher Talk, 32.

Moon, J. (2004). Reflection in Learning and Professional Development: Theory and Practice, Kogan Page, London.

Moon, J. (1999). Learning Journals: a handbook for academics. students and professional development. London: Kogan Page.

Osterman, K.F \& Kottamp, R.B. (2004). Reflective Practice for Educators. Thousand Oaks, CA: Corwin Press.

Pavlovich, K. (2007). The development of reflective practice through student journals. Higher Education Research and Development, 26(3): 281-295.

Phillips, P. (2008). Professional Development as a critical component of continuing teacher quality. Australian Journal of Teacher Education, 33 (1): 1-9.

Reid, B. (1993). 'But We're Doing it Already!' Exploring a Response to the Concept of Reflective Practice in Order to Improve its Facilitation. Nurse Education Today, 13: 305-309.

Reznitskaya, A. (2003). Philosophical Discussions in Elementary School Classrooms: Theory, Pedagogy, Research. Philosophical Discussions in Elementary School Classrooms: Theory, Pedagogy, Research. Montclair State University, New Jersey, USA.

Schön, D.A. (1983a). Reflective practitioner. (Chapter 2: From Technical rationality to reflection-in-action). Arena.

Schön, D.A. (1983b). The reflective practitioner: How professionals think in action. New York: Basic Books.

Schön, D. 1987. Educating the Reflective Practitioner: Towards a New Design for Teaching in the Professions, Jossey-Bass, San Francisco.

Timperley, H. (2008). Teacher professional learning and development. BElley: Imprimerie Nouvelle Gonnet.

Vandenberghe, R. (2002). Teachers' professional development as the core of school improvement. International Journal of Educational Research. 37(8): 653-659.

Yuan, Y. \& McKelvey, B. (2004). Situated Learning Theory: Adding Rate and Complexity Effects via Kauffman's NK Model. Nonlinear Dynamics, Psychology, and Life Sciences 8(1): 65-102.

Zeichner, K. \& Liston, D. (1996). Reflective Teaching: an introduction. Mahwah, New Jersey: Lawrence Erlbaum Associates.

Zeichner, K. (2008). A critical analysis of reflection as a goal for teacher education. Campinas Educ. Soc, 29(103). 